\title{
Prevalence of Impaired Glucose Regulation in Asymptomatic Kuwaiti Young Adults
}

\author{
Abdulnabi Alattar $^{\mathrm{a}}$ Hana Al-Majed ${ }^{\mathrm{b}}$ Thaier Almuailia ${ }^{\mathrm{a}}$ Obaid Almutairi ${ }^{\mathrm{a}}$ \\ ${\text { Amnah Shaghoulia }{ }^{\mathrm{a}} \text { Wehad Altorah }}^{\mathrm{a}}$

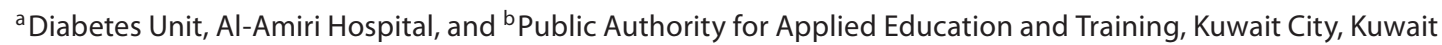

\section{Key Words}

Impaired glucose regulation - Kuwait - Young adults •

Diabetes $\cdot$ Obesity $\cdot$ Waist circumference $\cdot$ Oral glucose

tolerance test

\begin{abstract}
Objective: The objective of this study was to determine the prevalence of impaired glucose regulation in a young, asymptomatic Kuwaiti population. Subjects and Methods: A cross-sectional study of 484 Kuwaitis (females: 311, and males: 173 , aged 17-24 years), students at a public college for basic education, was conducted. Each participant underwent a 75-gram oral glucose tolerance test, and biochemical testing for hemoglobin $A_{1 c}\left(H_{b A} c\right)$, total cholesterol and triglyceride levels. Physical examinations were performed to measure body mass index (BMI), waist circumference and blood pressure. Results: The prevalence of impaired glucose regulation (impaired fasting glucose, impaired glucose tolerance, and elevated $\mathrm{HbA}_{1 \mathrm{c}}$ levels) was $32 \%$, including $4 \%$ with newly diagnosed diabetes. Of the 484 participants, 47 (10\%) of the population had hypertension and 52 (11\%) had dyslipidemia. A total of 244 (50\%) were classified as overweight/ obese (BMI $>25 \mathrm{~kg} / \mathrm{m}^{2}$ ) and 201 (42\%) had an elevated waist circumference ( $\geq 88 \mathrm{~cm}$ in females; $\geq 102 \mathrm{~cm}$ in males). Im-
\end{abstract}

paired glucose regulation was significantly related to increased waist circumference $(p=0.021)$ but not to increased BMI $(p=0.181)$. Those with impaired glucose regulation also had a higher prevalence of hypertension $(p=0.05)$, particularly systolic hypertension $(p=0.023)$. Conclusion: Kuwaiti youth have a high prevalence of impaired glucose regulation and overweight/obesity. Waist circumference, rather than $\mathrm{BMI}$, may be a more appropriate screening tool to predict impaired glucose regulation in Kuwaiti youth.

Copyright $\odot 2011$ S. Karger AG, Basel

\section{Introduction}

In adults, type 2 diabetes develops over a long period of time. Most, if not all, patients initially have impaired glucose tolerance, which is an intermediate stage in the natural history of type 2 diabetes and predicts the risk of the development of diabetes and cardiovascular disease $[1,2]$. The epidemic of obesity in Kuwait has been accompanied by a marked increase in the frequency of type 2 diabetes $[3,4]$. With appropriate lifestyle modification, progression from impaired glucose tolerance to overt diabetes can be delayed or prevented, and thus, great emphasis has recently been placed on the early detection of

\section{KARGER \\ Fax +41613061234 \\ E-Mail karger@karger.ch}

www.karger.com
(C) 2011 S. Karger AG, Basel

1011-7571/12/0211-0051\$38.00/0

Accessible online at:

www.karger.com/mpp
Abdulnabi T. Alattar

Al-Amiri Hospital, Sharq

Arabian Gulf Street, PO Box 4077

Safat 13041 (Kuwait)

Tel. +965 2245 0005, E-Mail abdul_2345@yahoo.com 
impaired glucose regulation $[5,6]$. We conducted this study to investigate the prevalence of impaired glucose regulation as a primary aim, and obesity as a secondary aim, in Kuwaiti youth, as there is no published data in this population. We chose this age group where lifestyle modification (if applied appropriately) might be of benefit in modifying the prevalence of diabetes in older age groups in the coming years [5-7].

\section{Subjects and Methods}

A total of 484 students who attended a college of basic education at the Public Authority for Applied Education and Training, Kuwait, between March 2009 and January 2010 were included in the study. We distributed flyers among the students over 4 weeks prior to the study, describing the project and inviting volunteers to participate in the study, followed by 2 lectures to describe and to answer any enquiries concerning the project. A total of 173 men and 311 women accepted to be included in the study. Participants were college students aged 17-24 years. Exclusion criteria were: neither clinical history (past or present) suggestive of diabetes nor being on treatment known to increase insulin resistance or induce diabetes, e.g. steroids, and (if female) participant not currently pregnant because plasma glucose levels and body mass index (BMI) values are influenced by both physiology and stage of pregnancy; no current acute infection. The exclusion criteria were assessed by direct interview with the participants by a specially trained nurse.

The study was approved by the Ethics Committee of the Ministry of Health, Kuwait. Informed consent was obtained from all the participants.

\section{Measures}

All measurements were taken by trained nurses in a specially designated clinic on the faculty campus. Individuals attended the clinic after an 8- to 14-hour fast. Participants underwent a 75gram oral glucose tolerance test using liquid glucose (Trutol ${ }^{\mathrm{TM}} 75$, glucose tolerance beverage, Thermo Fisher Scientific Inc.). Blood samples via finger prick were obtained for measurement of fasting blood glucose (as well as hemoglobin $\mathrm{A}_{1 \mathrm{c}}, \mathrm{HbA}_{1 \mathrm{c}}$, total cholesterol and triglycerides); additional blood samples were drawn after $120 \mathrm{~min}$ for postprandial blood glucose measurement. Body weight was measured with a Detecto weight/height scale to the nearest $0.5 \mathrm{~kg}$, and height was measured in centimeters using the same scale. BMI was calculated as weight in kilograms divided by the square of the height in meters. Blood glucose levels were tested using HemoCue Glucose 201+ with plasma converter $(\mathrm{He}-$ moCue Inc.). $\mathrm{HbA}_{1 \mathrm{c}}$ levels were measured using a DCA $2000+$ analyzer. Total cholesterol and triglycerides were tested using Afinion $^{\mathrm{TM}}$ AS100 analyzer.

\section{Definitions}

Type 2 diabetes was defined according to the American Diabetes Association criteria, i.e. fasting blood glucose $\geq 7$ $\mathrm{mmol} / \mathrm{l}$, and/or 2-hour postprandial glucose $\geq 11.1 \mathrm{mmol} / \mathrm{l}$, and/or $\mathrm{HbA}_{1 \mathrm{c}} \geq 6.5 \%$. Impaired glucose tolerance was defined as the presence of one or more of the following: fasting plasma
Table 1. Clinical characteristics of 484 Kuwaiti individuals aged 17-24 years

$\begin{array}{lc}\text { Gender } & \\ \quad \text { Male } & 173(35.7 \%) \\ \quad \text { Female } & 311(64.3 \%) \\ \text { Age, years } & 20.3 \pm 1.3 \\ \text { Family history of hypertension } & 181(41.7 \%) \\ \text { Family history of diabetes } & 245(50.6 \%) \\ \text { Current smoker } & 50(10.3 \%) \\ \text { BMI, kg/m }{ }^{2} & 26.3 \pm 6.7 \\ \text { Waist circumference, cm } & \\ \quad \text { Male } & 92.9 \pm 9 \\ \quad \text { Female } & 80.7 \pm 10.1 \\ \text { Systolic blood pressure, } \mathrm{mm} \mathrm{Hg} & 113.5 \pm 14.4 \\ \text { Diastolic blood pressure, } \mathrm{mm} \mathrm{Hg} & 74.2 \pm 9.4 \\ \text { Fasting blood glucose, } \mathrm{mmol} / \mathrm{l} & 4.9 \pm 0.7 \\ \text { 2-hour postprandial blood glucose, } \mathrm{mmol} / \mathrm{l} & 6.4 \pm 1.4 \\ \text { HbA } 1 \mathrm{c}, \% & 5.2 \pm 0.3 \\ \text { Total cholesterol, mmol/l } & 3.6 \pm 0.8 \\ \text { Triglycerides, mmol/l } & 1.3 \pm 0.7 \\ \end{array}$

Values are expressed as means \pm SD unless otherwise indicated.

glucose of $>5.6 /<7 \mathrm{mmol} / \mathrm{l}$, 2-hour postprandial glucose level of $>7.8 /<11.1 \mathrm{mmol} / \mathrm{l}$ and $\mathrm{HbA}_{1 \mathrm{c}}>5.6 /<6.5 \%$ [8]. Dyslipidemia was defined as triglyceride level $\geq 2.2 \mathrm{mmol} / \mathrm{l}$ and/or total cholesterol $\geq 5.6 \mathrm{mmol} / 1$ [9]. Hypertension was defined as systolic blood pressure $\geq 140 \mathrm{~mm} \mathrm{Hg}$ and/or diastolic blood pressure $\geq 90 \mathrm{~mm} \mathrm{Hg}$ [10]. Overweight was defined as BMI $>25 / \leq 30$ $\mathrm{kg} / \mathrm{m}^{2}$ and obesity as BMI $>30 \mathrm{~kg} / \mathrm{m}^{2}$. Elevated waist circumference was defined as $\geq 88 \mathrm{~cm}$ in females and $\geq 102 \mathrm{~cm}$ in males [9].

\section{Data Analysis}

Clinical characteristics were described using means and standard deviations for continuous variables and numbers and percentages for categorical data. All analyses were completed using SPSS version 17 for Windows (SPSS Inc., Chicago, Ill., USA). A 5\% level was chosen as a level of significance.

\section{Results}

The clinical characteristics of the 484 study participants are shown in table 1 . The female:male ratio was $2: 1$, representing the female:male ratio of the registered students in the collage at the time of the study. Family history of diabetes and hypertension was 50.6 and $41.7 \%$, respectively (reflecting the high prevalence of these conditions among Kuwaitis). On average, participants were overweight, with a mean BMI of $26.3 \pm 6.7 \mathrm{~kg} / \mathrm{m}^{2}$, with 244 (50.4\%) of the cohort being overweight and 96 (19.8\%) 
Table 2. Abnormalities detected in 484 Kuwaiti individuals aged 17-24 years

\begin{tabular}{|c|c|}
\hline Impaired glucose regulation $^{\mathrm{a}}$ & $155(32 \%)$ \\
\hline \multicolumn{2}{|l|}{ Hypertension (SBP $\geq 140 \mathrm{~mm} \mathrm{Hg}$ and/or } \\
\hline $\mathrm{DBP} \geq 90 \mathrm{~mm} \mathrm{Hg})$ & $47(9.7 \%)$ \\
\hline Dyslipidemia $^{\mathrm{b}}$ & $52(10.7 \%)$ \\
\hline Overweight (high BMI) & $244(50.4 \%)$ \\
\hline Overweight (high waist circumference) ${ }^{c}$ & $201(41.5 \%)$ \\
\hline
\end{tabular}

SBP = Systolic blood pressure; DBP = diastolic blood pressure.

a Includes impaired fasting glucose, impaired postprandial glucose, high levels of $\mathrm{HbA}_{1 \mathrm{c}}$ and participants diagnosed to have diabetes.

b Hypertriglyceridemia and/or hypercholesterolemia.

c Waist circumference $\geq 88 \mathrm{~cm}$ in females and $\geq 102 \mathrm{~cm}$ in males.

Table 3. Characteristics of 155 individuals with impaired glucose regulation out of the 484 study participants

\begin{tabular}{lll}
\hline Characteristics & $\begin{array}{l}\text { Impaired glucose } \\
\text { regulation }\end{array}$ & Diabetes \\
\hline Elevated fasting BG & $67(13.8 \%)$ & $6(1.2 \%)$ \\
Elevated 2-h postprandial BG & $62(12.8 \%)$ & $9(1.9 \%)$ \\
Elevated HbA $_{\text {lc }}$ & $45(9.3 \%)$ & $4(0.8 \%)$ \\
\hline
\end{tabular}

$\mathrm{BG}=$ Blood glucose. There is an overlap in the fasting, postprandial and level of $\mathrm{HbA}_{1 \mathrm{c}}$ in a number of participants.

obese. Mean waist circumference was within the normal range for females $(80.7 \pm 10.1 \mathrm{~cm})$ and males $(92.9 \pm$ $9 \mathrm{~cm})$, but $201(41.5 \%)$ of the study population were considered to have an elevated waist circumference. Hypertension was found in 47 (9.7\%) of the study group, and dyslipidemia in 52 (10.7\%) (table 2).

A total of 155 (32\%) of the participants had impaired glucose regulation. Of these, $138(28.5 \%)$ had prediabetes, which included impaired fasting plasma glucose in 67 (13.8\%), impaired 2-hour postload glucose in 62 (12.8\%), and $\mathrm{HbA}_{1 \mathrm{c}} \geq 6.5 \%$ in 45 (9.3\%). Newly diagnosed diabetes was found in 17 (3.9\%) subjects (table 3).

Those with glucose intolerance had significantly higher waist circumference than those with normal glucose tolerance ( 49 vs. $38 \% ; \mathrm{p}=0.021$ ), but BMI did not differ significantly between the groups (54.8 vs. $48.3 \%$; $\mathrm{p}=0.181)$. Although hypertension was marginally higher in glucose-intolerant subjects than in those with normal glucose tolerance ( 13.5 vs. $7.9 \%$; $p=0.05)$, systolic
Table 4. Clinical characteristics of patients with impaired glucose regulation

\begin{tabular}{|c|c|c|c|}
\hline \multirow[t]{2}{*}{ Variable } & \multicolumn{2}{|c|}{ Glucose regulation } & \multirow{2}{*}{$\begin{array}{l}\mathrm{p} \\
\text { value }\end{array}$} \\
\hline & $\begin{array}{l}\text { impaired } \\
(\mathrm{n}=155)\end{array}$ & $\begin{array}{l}\text { normal } \\
(\mathrm{n}=329)\end{array}$ & \\
\hline Female & $96(30.9)$ & $215(69.1)$ & 0.465 \\
\hline Male & $59(34.4)$ & $114(65.9)$ & \\
\hline Mean age $\pm S D$, years & $20.2 \pm 1.3$ & $20.4 \pm 1.3$ & 0.240 \\
\hline Family history of diabetes & $79(51)$ & $166(50.5)$ & 0.916 \\
\hline $\begin{array}{l}\text { Family history of hyperten- } \\
\text { sion }\end{array}$ & $74(47.7)$ & $128(38.9)$ & 0.066 \\
\hline Current smoker & $15(9.7)$ & $35(10.6)$ & 0.746 \\
\hline Diagnosis with hypertension & $21(13.5)$ & $26(7.9)$ & 0.05 \\
\hline Overweight by BMI & $85(54.8)$ & $159(48.3)$ & 0.162 \\
\hline $\begin{array}{l}\text { Overweight by waist } \\
\text { circumference }\end{array}$ & $79(49)$ & $125(38)$ & 0.021 \\
\hline Hypertriglyceridemia & $17(11)$ & $25(7.6)$ & 0.219 \\
\hline Hypercholesterolemia & $3(1.9)$ & $8(2.4)$ & 0.733 \\
\hline
\end{tabular}

Values are expressed as number of patients with percentage in parentheses unless otherwise indicated.

rather than diastolic hypertension was significantly related to impaired glucose regulation ( 9 vs. $4 \% ; \mathrm{p}=0.023$ ) (table 4).

\section{Discussion}

The high prevalence of $32 \%$ of impaired glucose regulation in our study population of Kuwaiti individuals aged $17-24$ years is similar to the $37 \%$ level found in a cohort of 491 European children and young adolescents aged 7-18 years [11]. However, it is higher than the $16 \%$ found in a survey of 2,689 US adolescents aged 12-19 years [12] and 27.5\% in 169 Turkish children (100 prepubertal, aged 7-11 years and 69 pubertal, aged 12-18) [13]. A possible explanation for the high prevalence of impaired glucose regulation in our population is the high prevalence of overweight and obesity: $73 \%$ of the general Kuwaiti population is overweight (BMI $\left.>25 \mathrm{~kg} / \mathrm{m}^{2}\right)$, and $40.6 \%$ is obese $\left(\mathrm{BMI}>30 \mathrm{~kg} / \mathrm{m}^{2}\right)$ [14]. In this study, the prevalence of $50.4 \%$ overweight, $19.8 \%$ obesity and $42 \%$ elevated waist circumference is higher than the $32 \%$ overweight/obesity rate reported by al-Isa [15] in 842 Kuwaiti University students, also higher than the $26.5 \%$ obesity rate found by Moussa et al. [16] in 2,400 Kuwaiti schoolchildren aged 6-13 years. The discrepancy between the $\mathrm{BMI}$ and waist circumference may be explained by an in- 
creased BMI in a number of nonobese male individuals due to increased muscle bulk. We found that waist circumference was significantly associated with impaired glucose regulation, while BMI was not. While elevated $\mathrm{BMI}$ is clearly a risk factor for many diseases and conditions, the excess deposition of fat in the abdominal region is more strongly associated with the metabolic disturbances thought to underlie many of the obesity-related conditions. Several indicators of abdominal obesity are available, but recent reports suggest that waist circumference is the most practical and accurate measure of abdominal obesity for use in public health research $[17,18]$.

There was no significant association between family history of diabetes and the prevalence of impaired glucose regulation in our population, though this is probably due to the very high prevalence of type 2 diabetes in the general Kuwaiti community [19], a similar phenomenon noted by other investigators when they studied a group of 167 Turkish children and adolescents for the prevalence of impaired glucose tolerance [13].

The prevalence of $10 \%$ hypertension in our study is within the range of $6.5-16 \%$ of previous studies [20, 21]. However, the prevalence was higher in individuals with impaired glucose regulation. This association reflects the fact that cardiovascular risk factors tend to cluster, a finding confirmed by others $[19,22]$.

Our study is limited by the fact that our cohort does not represent the 17-24 age group of the general Kuwaiti population in terms of sex distribution. The female:male distribution of the Kuwaiti population of the study age group in December 2009 was 1.02:1 [23] while in our study it is $2: 1$, yet this may not affect the overall estima- tion of prevalence of impaired glucose regulation, as there was no significant difference in the prevalence of impaired glucose regulation between both genders. Our selection criteria implied that only relatively highly educated young adults were included, which might have reflected lifestyle behaviors that are different from the general population, accordingly we would expect a higher prevalence of impaired glucose regulation if the sample studied was a random sample of the Kuwaiti population of the same age group.

\section{Conclusion}

Impaired glucose regulation is highly prevalent in young Kuwaiti adults aged 17-24; this condition is associated with a high prevalence of overweight/obesity. Our finding might be a warning of a future public health burden of diabetes and cardiovascular disease, which warrants preventive action. Further studies are needed in $\mathrm{Ku}-$ wait to confirm our results and to inform preventive action.

\section{Acknowledgments}

We would like to give special thanks to Dr. Ali Sadeq, consultant statistician from the Department of Biostatistics, Ministry of Health, for his valuable assistance in analyzing our data. We are also grateful to: Miss N. Aldebani, Miss S. Khattab, Mrs. S. Obaid and Mrs. S. Mol (nurses from the Ministry of Health, Kuwait) for their precious assistance in this project.

\section{References}

1 Saad MF, Knowler WC, Pettitt DJ, Nelson RG, Mott DM, Bennett PH: The natural history of impaired glucose tolerance in the Pima Indians. N Engl J Med 1988;319:15001506.

2 Diabetes Prevention Program Research Group: Reduction in the incidence of type 2 diabetes with lifestyle intervention or metformin. N Engl J Med 2002;346:393-403.

-3 Al Rashdan I, Al Nesef Y: Prevalence of overweight, obesity, and metabolic syndrome among adult Kuwaitis: results from community-based national survey. Angiology 2010; 61:42-48.
4 Abdella N, Al Nakhi A, Al Arouj M, Assoussi A, Moussa M: Impact of the 1997 American Diabetes Association criteria on classification of glucose intolerance among Kuwaitis below 50 years of age. Acta Diabetol 1999; $363: 133-140$.

-5 Meigs JB, Muller DC, Nathan DM, Blake DR, Andres R: The natural history of progression from normal glucose tolerance to type 2 diabetes in the Baltimore Longitudinal Study of Aging. Diabetes 2003;52:1475-1484.

6 Lindström J, et al: Prevention of diabetes mellitus in subjects with impaired glucose tolerance in the Finnish Diabetes Prevention Study: results from a randomized clinical trial. J Am Soc Nephrol 2003;14:S108S113.
7 Matti I, Uusitupa J: Early lifestyle intervention in patients with non-insulin-dependent diabetes mellitus and impaired glucose tolerance. Ann Med 1996;28:445-449.

8 American Diabetes Association: Diagnosis and classification of diabetes mellitus. Diabetes Care 2010;(suppl 1):S62-S69.

9 National Heart, Lung, and Blood Institute: Third Report of the National Cholesterol Education (NCEP) Expert Panel on Detection, Evaluation, and Treatment of High Blood Cholesterol in Adults (Adult Treatment Panel III) final report. Circulation 2002;106: 3143-3421. 
10 National Heart, Lung, and Blood Institute: The Seventh Report of the Joint National Committee on Prevention, Detection, Evaluation, and Treatment of High Blood Pressure. Bethesda, 2004, pp 11-12.

11 Wiegand S, Maikowski U, Blankenstein O, Biebermann H, Tarnow P, Grüters A: Type 2 diabetes and impaired glucose tolerance in European children and adolescents with obesity - a problem that is no longer restricted to minority groups. Eur J Endocrinol 2004;151:199-206.

12 Li C, Ford ES, Zhao G, Mokdad AH: Prevalence of pre-diabetes and its association with clustering of cardiometabolic risk factors and hyperinsulinemia among U.S. adolescents. Diabetes Care 2009;32:342-347.

13 Atabek ME, Pirgon O, Kurtoglu S: Prevalence of metabolic syndrome in obese Turkish children and adolescents. Diabetes Res Clin Pract 2006;72:315-321.
14 Al-Isa AN: Changes in body mass index and prevalence of obesity among adult Kuwaiti woman attending health clinics. Ann Saudi Med 1997;17:307-311.

15 al-Isa AN: Obesity among Kuwait University students: an explorative study. JR Soc Promot Health 1999;119:223-227.

16 Moussa MAA, Shaltout AA, Al-Sheikh N Agha N: Prevalence of obesity among 6- to 13-year-old Kuwaiti children. Med Princ Pract 1999;8:272-280.

$\checkmark 17$ Booth ML, Hunter C, Gore CJ, Bauman A, Owen $\mathrm{N}$ : The relationship between body mass index and waist circumference: implications for estimates of the population prevalence of overweight. Int J Obes Relat Metab Disord 2000;24:1058-1061.

18 Janssen I, Katzmarzyk PT, Ross R: Waist circumference and not body mass index explains obesity related health risk. Am J Clin Nutr 2004;79:379-384.
19 Abdella N, Al Arouj M, Al Nakhi A, Al Assoussi A, Moussa M: Non-insulin-dependent diabetes in Kuwait: prevalence rates and associated risk factors. Diabetes Res Clin Pract 1998;42:187-196.

20 Al-Jarky F, Al-Awadhi N, Al-Fadli H, Tawfic AS, Al-Sebai AR, Al Mousawi M: Prevalence of hypertension in young and middle aged Kuwaiti citizens in Primary Health Care. Kuwait Med J 2005;37:116-119.

21 Badr HE, Al Orifan FH, Amasha MMF, Khadadah KE, Younis HH, Sabour Se'adah MA: Prevalence of metabolic syndrome among healthy Kuwaiti adults: Primary health care centers based study. Middle East J Family Med 2008;5:8-11.

-22 Falkner B, Sherif K, Sumner AE, Kushner H Blood pressure increase with impaired glucose tolerance in young adult American Blacks. Hypertension 1999;34:1086-1090.

23 Public authority for civil information; http:// www.paci.gov.kw/. 